\title{
Journal of Thermal Spray Technology Volume 20 Best Paper Awards
}

The Journal of Thermal Spray Technology (JTST) is delighted to announce the winners of the JTST Volume 20 Best Papers Awards, as chosen by an international committee of expert judges. The awards were presented to the winning authors at the International Thermal Spray Conference \& Exposition 2012, in Houston, Texas.

The Editorial Committee and International Board of Review of the journal believe it is important to evaluate the
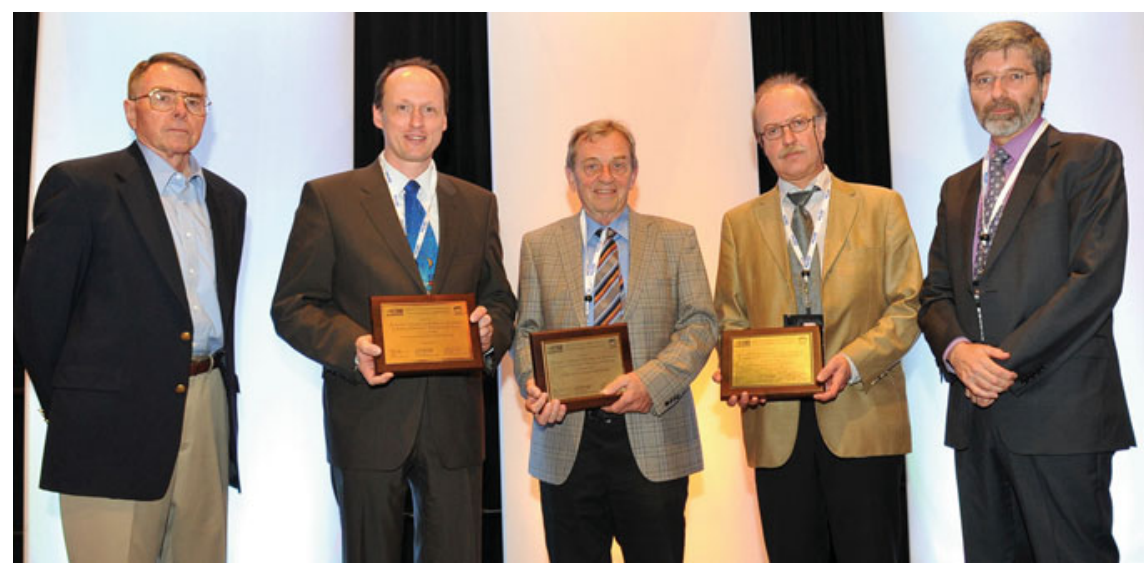

Journal of Thermal Spray Technology Committee Chair Robert Tucker (far left) and Editor-in-Chief Christian Moreau (right) present the JTST Volume 20 Best Paper Award to (remaining from left) Thomas Klassen, Heinrich Kreye, and Frank Gärtner for their paper "On Parameter Selection in Cold Spraying."

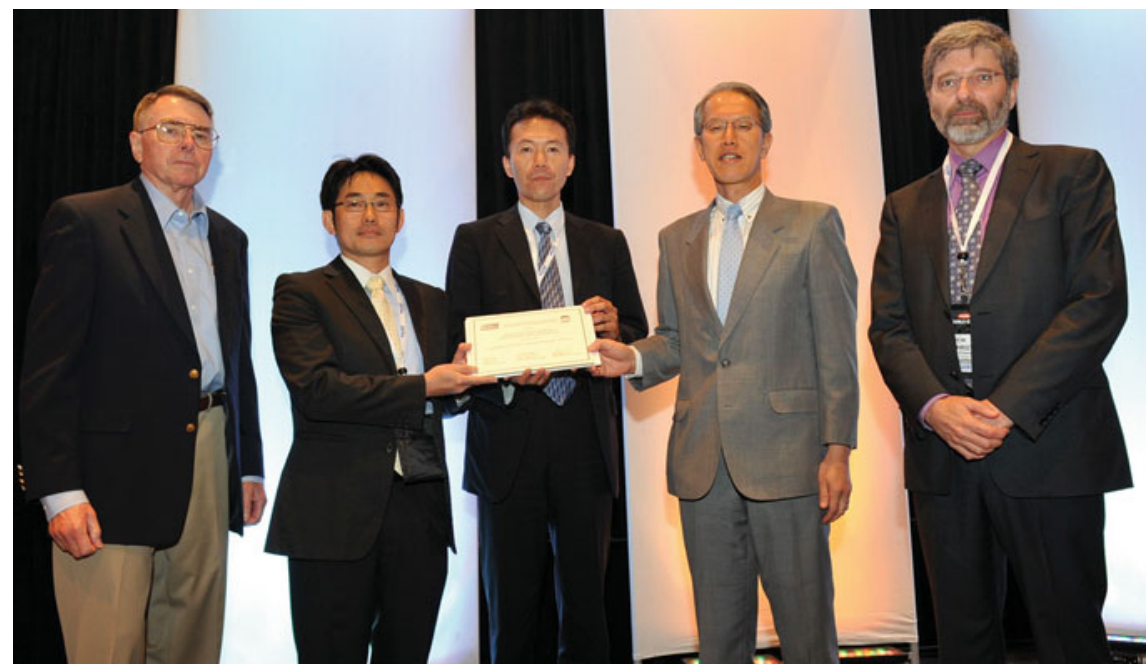

The Outstanding Review Paper Citation was presented by Robert Tucker and Christian Moreau to (center, from left) Makoto Watanabe, Hiroshi Katanoda, and Seiji Kuroda for their paper "Current Status and Future Prospects of Warm Spray Technology." quality of engineering and scientific contributions published in JTST and to provide recognition of excellent work and its publication. Each paper is reviewed and evaluated on its merits for scientific and engineering content, originality, and presentation style. The following papers are recognized as outstanding and the authors received awards of recognition for their excellent publications.

The Journal of Thermal Spray Technology Volume 20 Best Paper Award:

"On Parameter Selection in Cold Spraying" by Hamid Assadi, Tobias Schmidt, Horst Richter, Jan-Oliver Kliemann, Kurt Binder, Frank Gärtner, Thomas Klassen, and Heinrich Kreye, Helmut Schmidt University (Prof. Assadi is also affiliated with Tarbiat Modares University and Prof. Richter is also affiliated with Thayer School of Engineering, Dartmouth College.)

The Journal of Thermal Spray Technology Volume 20 Outstanding Review Paper Citation:

"Current Status and Future Prospects of Warm Spray Technology" by Seiji Kuroda, Makoto Watanabe, KeeHyun Kim, National Institute for Material Science (NIMS), and Hiroshi Katanoda, Kagoshima University.

The international committee of judges, led by Dr. Roland Seals, chair of the Journal of Thermal Spray Technology Best Paper Subcommittee, is as follows: Arvind Agarwal, David Bucci, Andrew Gouldstone, Jan Ilavsky, George Kim, KeeHyun Kim, Anand A. Kulkarni, Seiji Kuroda, Jiri Matejicek, Tim McKechnie, Shiladitya Paul, James A. Ruud, Richard Schmid, Igor Sevostianov, Philip Shipway, Yoshiki Tsunekawa, Alfredo Valarezo, Joel Voyer, and Makoto Watanabe.

Congratulations are extended to the winning authors from the JTST Editorial Board and the ASM Thermal Spray Society Executive Board of Directors. 